\title{
Electrical Properties of Fluoro-Containing Alicyclic Polyimides
}

\author{
Valentina Kravtsova $^{1}$, Maira Umerzakova ${ }^{1}$, Rinat Iskakov $^{2}$ and Natalia Korobova ${ }^{3 *}$ \\ 1. Institute of Chemical Science, Almaty 050010, Kazakhstan \\ 2. Chemical Engineering School, Kazakh-British Technical University, Almaty 050000, Kazakhstan \\ 3. National Research University of Electronic Technology, Zelenograd 124498, Russia
}

\begin{abstract}
The electrical, physical, mechanical and thermal properties of fluorine-containing alicyclic polyimides have been investigated. It was shown that the minimum value of the dielectric constant 1.91 at room temperature and $1 \mathrm{kHz}$ frequency was achieved for polymers containing only one fluorine atom in the structure. The dielectric loss tangent of new polymers was (1-4) $\times 10^{-3}$. Electro-physical parameters were stable during polymer heating up to $300{ }^{\circ} \mathrm{C}$, and at the frequency from 1 to $20 \mathrm{kHz}$. Resistivity by heating in the air up to $320-380{ }^{\circ} \mathrm{C}$ has been investigated depending on the polyimides structure. The coefficient of moisture absorption for the fluorine-containing polyimide based on dianhydride with 4,4'-oxydianiline was determined at 50\% humidity and $25{ }^{\circ} \mathrm{C}$. It was around 0.6 , but after immersion in the water for 24 and $48 \mathrm{~h}$ was $0.8 \%$ and $1.2 \%$, respectively. Manufactured films had tensile strength to $160-170 \mathrm{MPa}$, and elongation up to $55 \%$.
\end{abstract}

Key words: Fluoro-containing alicyclic polyimides, composition, electrical, physical properties.

\section{Introduction}

In recent years wide range of heat-resistant polymer materials with high levels of electro-physical characteristics has been successfully used as insulating materials in many technical fields [1-3]. Polymers with low dielectric constants are in particular interest and highly used in microelectronics as interlayer dielectrics in integrated circuits $[4,5]$, antenna technology [6], production of radio-materials for mechanical protection transmitting devices [7], and so on. Substantial progress in this area to date has been achieved in the application of aromatic polyimides as basic polymers. Complex of physico-mechanical properties of these polymers with alicyclic polyimides fragments and fluorine atoms in the structure best fits the microelectronic requirements [8-10].

Such polymer polyimides based on dianhydrides of tri-cyclodecentetracarbon acids $[11,12]$ were developed by the authors of this paper. High thermal

\footnotetext{
*Corresponding author: Natalia Korobova, Professor/Dr., research field: materials for microelectronics. E-mail: korobova3@mail.ru.
}

stability, ability to maintain dielectric, physical and mechanical properties over a wide temperature range, low thermal expansion, accessibility and adaptability for production are their advantages. Furthermore, they form stable compounds with many different compositions [12, 13], which allows to obtain new materials with desired parameters. Also dielectric loss tangent there is a very important factor determining the electric field behavior in the dielectric in addition to dielectric constant. It is necessary to establish the factors influencing their electrical properties for targeted properties regulation and development of materials with the desired characteristics set. The aim of this work is to study the dielectric constant and dielectric loss tangent of fluorinated alicyclic polyimides and their compositions with polypyromellitimides depending on the temperature and electric field frequency.

\section{Experiments}

Developed previously $[12,13]$ fluorinated alicyclic polyimides and their compositions with some 
industrial polymer such as polypyromellitimide lacquer brand AD-9103 (Russia) are the study objects. The samples were prepared on glass substrate in the film form with thickness $40 \pm 5 \mathrm{um}$, which was dried by heating under vacuum up to $300{ }^{\circ} \mathrm{C}$.

The following film properties were investigated:

(1) Electrical characteristics: dielectric constant $\varepsilon$ and the dielectric loss tangent $\tan \delta$. Films dielectric constant and $\tan \delta$ frequency dependence were measured on Alfa-A-Analyzer (Novocontrol) with Active cell ZGS-1200 and CRL digital meter model E7-8 electric field at frequencies of 1,10 and $20 \mathrm{kHz}$ at temperatures ranging (from -100 to $400{ }^{\circ} \mathrm{C}$ ) [14];

(2) Coefficient of moisture absorption at $50 \% \mathrm{RH}$ and after immersion in water for 24 and $48 \mathrm{~h}$ according to the procedure described in [15];

(3) Temperature characteristics (glass transition and decomposition temperatures) were measured by TGA-SDTA (thermo-gravimetric analysis and simultaneous difference thermal analysis) by thermo-gravimeter "Mettler Toledo" (Switzerland) at temperature rise rate $8{ }^{\circ} \mathrm{C} / \mathrm{min}$ coupled with micro-calorimeter of the same company;

(4) Mechanical tests to determine the tensile strength $(\sigma)$, elongation $(l)$ and elastic modulus (E) were carried out on tensile testing machine Com-Ten Testing Equipment (USA).

\section{Results and Discussion}

It is known that the dielectric properties of polymeric materials of the certain level, in particular, the low dielectric constant values and dielectric loss tangent makes ability to provide materials for rapid heating in an alternating electric field of high frequency. The materials use with such properties as insulating layers in nano-circuits allows significantly increase propagation speed of electrical signals, etc.. Many factors that must be considered in the products formation, which effect on the dielectric properties. For example, the dielectric constant of polymer depends on the chemical structure, polarizability, free volume, hydrophobicity, as well as the external conditions (temperature, degree of environment ionization, humidity, frequency and the electric field intensity, current and others). These factors largely determine the dielectric loss. When considering the dependence of the dielectric polyimides properties from the first group of these factors has been observed $[5,16]$ that their contribution to the value of polymers dielectric constant can vary significantly during the transition from one structure to another. The effective application of such materials in addition to the low values of dielectric constant and $\tan \delta$ must be mechanically strong and thermally stable in micro-, nano-electronics and other fields. This is due to the necessity of using electronic devices in a variety of (sometimes aggressive) environments. All this makes it necessary to carry out studies for each new type of polymer.

In the course of this research dielectric constant and dielectric loss tangent, basic mechanical and thermal properties of fluorine-containing alicyclic polymers of tricyclodecen structures in the main chain and their tracks with one of the most well-known heat-resistant polymers-polypyromellitimides have been determined. Temperature and frequency of the electric field influence on the electrical parameters, as well as the ambient humidity were considered. The glass transition temperature data knowledge of which is necessary for the processing of polymeric materials have been listed below. Investigations were carried out on samples of three films groups. First group included polyimides based on fluorine-containing dianhydride and diamine three-FPI-1 (4,4'-oxydianiline), FPI-2 (p-xylylene diamine) and FPI-3 (hexamethylene diamine), respectively. The second group was FPI-2 and FPI-3 samples with a porous microstructure, and third group includes FPI-1 composition with $\mathrm{PI}_{\mathrm{PM}}$ (polypyromellitimides).

Table 1 summarizes data for FPI 1-3 polymer films with dielectric constant values compared with their unsubstituted analogue (PI) and polypyromellitimides (PI $\left.{ }_{P M}\right)$ of AD 9103 varnish. 
Table 1 Dielectric permeability and physico-mechanical properties of alicyclic FPI $\left(25^{\circ} \mathrm{C}\right)$.

\begin{tabular}{lllll}
\hline \multirow{2}{*}{ Polymer } & $\varepsilon$ & \multicolumn{3}{c}{ Physico-mechanical parameters } \\
\cline { 3 - 5 } & $(1 \mathrm{kHz})$ & $\sigma_{\mathrm{b}}(\mathrm{MPa})$ & $\mathrm{E}(\mathrm{MPa})$ & $l(\%)$ \\
\hline FPI-1 & 1.91 & 160 & 4,200 & 30 \\
FPI-2 & 3.14 & 110 & 3335 & 30 \\
FPI-3 & 3.52 & 90 & 2910 & 37 \\
PI & 2.84 & 140 & 4350 & 24 \\
PI $_{\text {PM }}[5]$ & $3.0-3.5$ & $150-170$ & - & $45-70$ \\
\hline
\end{tabular}

Table 1 shows that the alicyclic polyimides containing only one fluorine atom in the structure characterized by lower dielectric permittivity compared to polypyromellitimides. This is due to the polymer structure, namely an alicyclic structure and a halogen atom in tricyclodecen fragment affect the free volume of the polymer unit and macromolecules in general, increasing the effect. In the case of aromatic polyimide dielectric permeability decreases from 3.0-3.5 to 2.5-2.9 provided that the presence in the polymer unit of six to 15 fluorine atoms $[1,5,16,17]$. However, these values are somewhat higher than the alicyclic polyimide FPI-1 one.

Polymers for use in microelectronics play importance in certain performances such as water resistance index $[5,18,19]$. Table 1 shows the values dielectric permeability of polyimides at a relative humidity of $20 \%$. After exposing polyimide films in water the permittivity values for studied FPIs change slightly to 2.01-3.62. The moisture absorption coefficient at $25{ }^{\circ} \mathrm{C}$ for certain polymers FPI 1-3 at $50 \%$ at room temperature moisture was 0.6 , after immersion in water for 24 and $48 \mathrm{~h}$ were $0.8 \%$ and $1.2 \%$, respectively. These values were correlated with the data for fluorinated aromatic polyimides for which it was $1.1 \%-2.6 \%[5,16]$. Many polyimides have higher moisture absorption amounting to $2.5 \%-3 \%$. In general, compared to the aromatic polyimide polymers FPI 1-3 were more water resistant polymers with low water and moisture absorption due to their structure peculiarities.

Dependence study of the dielectric constant on the temperature showed parameter stability for polymers developed in a wide range of temperatures. Table 2 shows the values for positive temperatures dielectric permeability.

It can be seen that FPI-1 permeability value at $25{ }^{\circ} \mathrm{C}$ and $1 \mathrm{kHz}$ is 1.91 ; and at $100{ }^{\circ} \mathrm{C}$ at the same frequency is 1.93 , in the range of $200-300{ }^{\circ} \mathrm{C}$ this parameter lies in the range of 1.88-2.01, respectively. Similar pattern was obtained for the FPI-2 and FPI-3 ones. Increasing the dielectric constant starts after $300^{\circ} \mathrm{C}$. This is associated with a significant increase flexibility of the polymer chains and their subsequent destruction, leading to the formation of decomposition products with different dielectric constants. It is a characteristic feature of this class of polymers as polyimides [16, 20, 21]. This parameter does not change when you change the frequency of the electric field from 1 to $20 \mathrm{kHz}$. The absolute value $\varepsilon$ of alicyclic polyimides are approaching carbon-chain fluorinated polymers and widely used in electron optics [5]. Relatively dielectric permeability of FPI-2 and FPI-3 polymers should be noted that this option, as shown in Tables 1 and 2 to aliphatic-aromatic polyimide and aliphatic groups in the structure is somewhat higher compared with the FPI-1. Researchers are making great efforts to reduce the dielectric constants of some materials. One method consists in giving them the porous microstructure [22, 23]. Practical ways to implement it are different. We have developed a method for producing a porous film material, based on the addition to the polymer solution prior to forming the films a small amount of oligo-dimethyl-siloxane. This compound in an amount of $1 \%-1.5 \%$ exerts a positive influence on $\varepsilon$ and at the same time does not cause changes in other

Table 2 Dielectric permeability of alicyclic FPI at various temperature (1 kHz).

\begin{tabular}{lllll}
\hline \multirow{2}{*}{ Polymer } & \multicolumn{4}{c}{ Temperature $\left({ }^{\circ} \mathrm{C}\right)$} \\
\cline { 2 - 5 } & 25 & 100 & 200 & 300 \\
\hline FPI-1 & 1.91 & 1.93 & 1.88 & 2.01 \\
FPI-2 & 3.14 & 3.11 & 3.10 & 2.28 \\
FPI-3 & 3.52 & 3.56 & 3.60 & 3.70 \\
PI & 2.84 & 2.85 & 2.83 & 2.94 \\
\hline
\end{tabular}


characteristics [24]. Fig. 1 shows the surface films FPI-2 topography with different number of pores.

The values of the dielectric constant films were changed as follows: in the case of FPI-2 from 3.14 (a) to 2.71 (b) and 2.43 (c). Similar porous samples were obtained on the basis of FPI-3 ones.

These data suggest that the dielectric constant of the fluorine-containing alicyclic polyimide can be adjusted both by the chemical structure and by introducing pore obtain materials with predetermined parameters. Presented in this paper polymers, as well as other members of polyimides class, refer to the midrange of the dielectrics. The symmetrical arrangement of the polar carbonyl groups, as seen from the below-mentioned general formula of investigated FPI, provides low dielectric loss level typical for polyimides [16]. Depending on the chemical structure of the investigated fluorinated

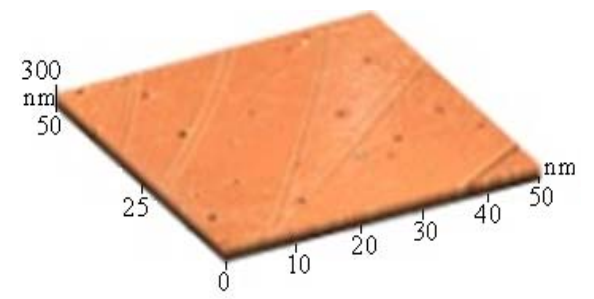

(a)

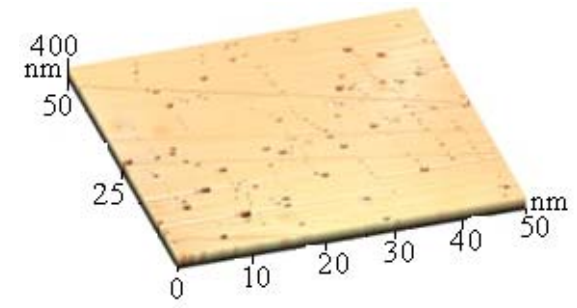

(b)

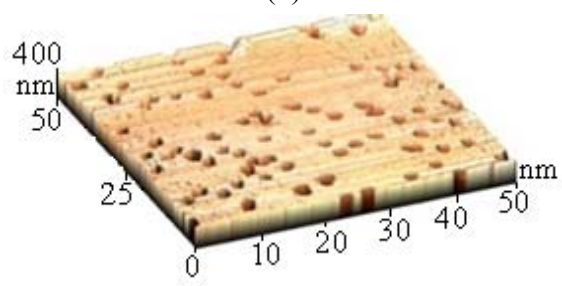

(c)

Fig. 1 AFM-images of surfaces FPI-2 films with various level of porosity: (a) initial polyimide film, (b) and (c) samples with dielectric permeability 2.71 and 2.43, respectively. alicyclic polyimides value of dielectric loss is around $(1-4) \times 10^{-3} \quad[13,14]$. Increasing dielectric loss associated with the degradation products formation in the case of FPI- 1 ones are registered at $380{ }^{\circ} \mathrm{C}$ and for FPI-2 and FPI-3 ones at temperature of 340 and $320^{\circ} \mathrm{C}$, respectively. These changes, as well as for the dielectric permeability are due to the effect of low molecular weight of degradation products, those increase the concentration of dipoles.

It should be noted feature of $\tan \delta$, having great practical importance. Substantial change in the dielectric loss tangent from $0.01-0.02$ to $0.001-0.003$ should be noted during transition from polyamic acid polymer form, which is due to a sharp decline in the number of groups, causing the loss of the dipole [25]. In practical materials use with enough high imidization degree various complications can arise until the output of the equipment failure. Therefore it is necessary to fulfill the conditions that ensure the transformation into the final polyimide pre-polymers and available to control this process by a method, especially in a production environment. These methods based on measurement relates dielectric loss factor as the most sensitive parameter indicating changes in thermal processing of polymers, a dielectric method $[25,26]$. The above heating mode of films to $300{ }^{\circ} \mathrm{C}$ is associated with the need to transfer present 5\%-7\% acid-amide groups of molded films on glass substrates. The values of $\tan \delta$ were ranged from 0.007-0.009 to 0.001-0.003 indicating preparation of polyimides with a quantitative degree of imidization $(\approx 100 \%)$ [25]. The activation energy of the relaxation transitions was calculated for the temperature dependence of $\tan \delta$-T of FPI-1 ones as a curve with three small peaks: for the relaxation process in subzero temperature (from -100 to $-25^{\circ} \mathrm{C}$ ) was found as $52.50 \mathrm{~kJ} / \mathrm{mol}$; and for intervals $\left(40-180{ }^{\circ} \mathrm{C}\right)$ and $\left(200-290{ }^{\circ} \mathrm{C}\right) \quad-140.98$ and $498.27 \mathrm{~kJ} / \mathrm{mol}$, respectively. In the case of $\mathrm{PI}_{\mathrm{PM}}$, the activation energy value defined for the similar transitions. It was at the level of 60,140 and $670 \mathrm{~kJ} / \mathrm{mol}$ accordingly [25, 26]. 
Smaller activation energy values of the relaxation transitions can be explained by more rapid transition to fluorinated alicyclic polyimides compared with polypyromellitimide one due to the greater flexibility of the elementary units. Additional requirements for electrical insulating materials were imposed by the conditions of the operation product. Among the requirements for reliability include the need to obtain materials with high thermal and mechanical properties $[5,16]$. The synthesized polyimides belong to the class of thermo-stable polymers. Their thermal properties were estimated by TGA and DSK. As you can see from Table 3, investigated polymers begin to degrade in air at temperatures of $320-380{ }^{\circ} \mathrm{C}$ depending on the structure.

In an inert gas atmosphere, they begin to decompose at higher temperature. Glass transition temperature of polymers was listed in Table 3. The difference between $T_{g}$ and decomposition temperature in air was from 20 to $60^{\circ} \mathrm{C}$, which will be used in the sample preparation process by thermoforming.

Good solubility of the fluorine-containing alicyclic polyimide in organic solvents and sufficiently high molecular weight were led to production of such polymer colorless films, which mechanical properties you have seen in the Table 1. It is noted that, depending on the polymer structure $\sigma_{\mathrm{p}}$ tensile strength and elongation at break were equal to $90-160 \mathrm{MPa}$ and 24\%-30\% respectively. Analyzing the mechanical properties of alicyclic polyimide films it may be noted that they are characterized by both high strength and average values of elongation in other hand, which could be a limiting factor in their practical application in certain areas. This disadvantage can be eliminated

Table 3 Thermal parameters of alicyclic fluoro-containing polyimides.

\begin{tabular}{llll}
\hline \multirow{2}{*}{ Polymers } & \multicolumn{3}{c}{$T_{d}\left({ }^{\circ} \mathrm{C}\right)$} \\
\cline { 2 - 4 } & Air & Argon & $T_{g}\left({ }^{\circ} \mathrm{C}\right)$ \\
\hline FPI-1 & 380 & 435 & 305 \\
FPI-2 & 340 & 380 & 280 \\
FPI-3 & 320 & 355 & 260 \\
PI & 365 & 415 & 325 \\
\hline
\end{tabular}

by a modification of FPI. It will be possible to use other elastic macromolecular compounds, particularly well-known commercial polymer-PI $\mathrm{PM}_{\mathrm{PM}}$, which films of different thicknesses are characterized by an elongation from $45 \%$ to $70 \%$ at break $[16,18,27]$. Taking into account increased $\tan \delta$ values compared to FPI polymer composition concentration was adjusted so that this parameter has not changed substantially. Table 4 shows the values of the dielectric constant and mechanical properties of the samples from third group of FPI-1 composite films with varying $\mathrm{PI}_{\mathrm{PM}}$ amounts.

The reduced elongation of the FPI-2 and FPI-3 modified films was increased up to $50 \%$ and $55 \%$, respectively. Moreover, their strength increased by 20-30 MPa. More than 10 wt.\% of the modifying polymer was not added in the composition as further increasing the mechanical characteristics of the films do not occur. Table 4 also shows that the dielectric permeability values of the composite films lower than polypyromellitimide ones. Furthermore, modulus for composite films was lower than the starting polyimide. The film becomes more elastic, because of plasticizing polypyromellitimides action. Therefore, modification of alicyclic polyimides by aromatic nature polymer can improve their physical, mechanical and thermal properties, and the electrical parameters retain their high value.

Thermal properties investigation of composite films has been showed that thermal stability of the new material compared with the initial FPI-1 becomes higher by $15-20{ }^{\circ} \mathrm{C}$ due to the matrix of aromatic polyimide. Further effect of this polymer was shown

Table 4 Dielectric permeability and mechanical properties of FPI-1 composite films $\left(25^{\circ} \mathrm{C}, 1 \mathrm{kHz}\right)$.

\begin{tabular}{lllll}
\hline $\mathrm{PI}_{\mathrm{PM}}$ & $\mathrm{3}$ & \multicolumn{3}{c}{ Physico-mechanical characteristics } \\
\cline { 3 - 5 } $\begin{array}{l}\text { concent-ration } \\
\text { in FPI-1 }\end{array}$ & $\begin{array}{l}\mathrm{E} \\
(1 \mathrm{kHz})\end{array}$ & $\sigma_{b}(\mathrm{MPa})$ & $E(\mathrm{MPa})$ & $l(\%)$ \\
\hline 0 & 1.91 & 160 & 4200 & 30 \\
2.5 & 1.95 & 165 & 4100 & 35 \\
5.0 & 2.03 & 167 & 3740 & 38 \\
7.5 & 2.34 & 170 & 3600 & 40 \\
10.0 & 2.73 & 170 & 3500 & 45 \\
\hline
\end{tabular}




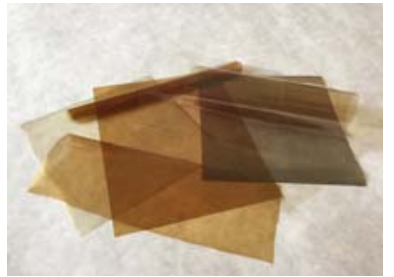

(a)

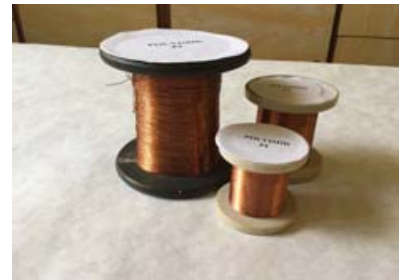

(b)
Fig. 2 Samples of polyimide film (a); enamel-wire (b) from alicyclic polyimides.

in the modification of FPI-2 and FPI-3 ones. For these samples we have seen the increase in thermal stability at 25 and $30{ }^{\circ} \mathrm{C}$, respectively. The new insulating material (Fig. 2) becomes more flexible due to the plasticizing action $\mathrm{PI}_{\mathrm{PM}}$.

Experimental samples of new films and heat-resistant enamel wires were obtained from the developed polyimides. Films were obtained in the scientific laboratory. Enamel copper wire was carried out in Russia in the enterprise "Sibkabel" (Tomsk) and Kazakhstan in the company "Kentau Transformer Plant". Studies have shown that in addition to the film-forming properties alicyclic polyimides exhibit good enameled ability.

\section{Conclusions}

From the currently known works of theoretical and applied nature, devoted to the creation of polymer materials for microelectronics, polyimides meet the most technical requirements imposed on such materials. Tightening of these requirements stimulates the search for new polymers and related materials with higher levels of individual characteristics. These polymers include fluorinated alicyclic polyimides and their composition with the polymer industry-polypyromellitimides. The study of the major electrical, mechanical and thermal properties of the new polyimides showed that the inclusion of only one fluorine atom in tricyclodecen structure allows to obtain polymers with a low dielectric constant and dielectric loss level in the temperature range from -100 to $+300{ }^{\circ} \mathrm{C}$ at the same time with high mechanical and thermal properties. The synthesized polymers are stable in air up to $320-380{ }^{\circ} \mathrm{C}$.

Presence of a fluorine atom and an alicyclic structure is a key solution in problem of polymer hydro-phobization due to the reduction of moisture absorption, which together with the solubility in organic solvents can be potentially used for printing the micro- and nano-items for microelectronics. Films prepared in the compositions with a more flexible aromatic polyimide have a tensile strength up to $170 \mathrm{MPa}$ and elongation up to $55 \%$. The results obtained in the present study are responsible for the possibility to apply fluorinated alicyclic polyimides for micro- and nanoelectronics, electrical engineering and other techniques.

\section{Acknowledgments}

This work was financially supported by the Ministry of Education and Science of the Republic of Kazakhstan in the framework of the state order on "The theoretical basis for the creation of new polymer composite materials with special properties" (2015-2017).

\section{References}

[1] Hasegava, M., and Horie, K. 2001. "Photophysics, Photochemistry and Optical Properties of Polyimides." Prog. Polym. Sci. 26: 259-335.

[2] Blythe, E. E. R., and Blur, D. 2005. Electrical Properties of Polymers. Cambridge: Cambridge Univ. Press.

[3] Milinchuk, V. K., Klinshpont, E. R., Shelukhov, I. P., and Smirnova, T. N. 2002. "Degradation of Polymeric Materials on Orbital Space Station "Mir"." Russian J. Nuclear Power. Izv. Vuzov. 2: 108-118.

[4] Dolgovykh, Y., Pogalov, A., Blinov, G., Timoshenkov, S., and Korobova, N. 2014. "Mounting Uncased Multi-connection Integrated Circuits with Ball Contacts on Flexible Polyimide Board." In Proceedings of the International Conference on Future Information \& Communication Engineering 288-291.

[5] Rusanov, A. L., Stadnik, T. A., and Mullen, K. 1999. "New Condensation Polymers Having Low Dielectric Constants." Russian J. of Uspekhi Khimii. 68: 760-772.

[6] Zerov, V. Y., Malyaro, V. G., and Khrebtov, I. A. 2011. "Antenna Related Microbolometers." Opt. J. 78 (5): 31-43.

[7] Vertyanov, D., Timoshenkov, S., Golishnikov, A., 
Nazarov, E., Putrya, M., and Korobova, N. 2014. "Deep Plasma Etching Process Investigation of Polyimide Materials for Forming Interlayer Connections in Microelectronic Nodes." In Proceedings of IEEE XXXIV International Scientific Conference Electronics and Nanotechnology (ELNANO), 54-58.

[8] Wang, H., Tao, X., and Newton, E. 2002. "Dielectric Properties of Fluoride-Containing Polymethylsiloxane-Imide Films." High Performance Polymers 14: 271-283.

[9] Matsumoto, T., Mikami, D., and Hashimoto, E. 2009. "Alicyclic Polyimides-A Colorless and Thermally Stable Polymer for Opto-Electronic Devices." J. of Physics: Conf. Ser. 187 (3): 1-11

[10] Hulubei, C., and Popovici, D. 2011. "Novel Polyimides Containing Alicyclic Units Synthesis and Characterization." Rev. Roum. Chem. 56: 209-215.

[11] Zhubanov, B. A., Kravtsova, V. D., and Iskakov, R. M. 2008. "Polymeric Composites Based on Alicyclic Polyimide and Polyaniline." Rus. J. of Applied Chemistry 81 (12): 2151-2154.

[12] Zhubanov, B. A., Umersakova, M. B., Kravtsova, V. D., Iskakov, R. M., and Sarieva, R. B. 2013. "New Polymeric Composition on the Basis of Alicyclic Polyimides and Polyethylene Glycol." In Proceedings of 2 International Academic Conference Applied and Fundamental Studies, 8-10.

[13] Zhubanov, B. A., Kravtsova, V. D., Mukhamedova, R. F., and Bekmagambetova, K. 2006. "Nev Polymeric Systems on Alicyclic Polyimides." Rus. J. of Applied Chemistry 79 (11): 1890-1895.

[14] Lushcheikin, G. A. 1988. Methods of Study of the Electrical Properties of Polymers. M.: Chemistry.

[15] Solid Electrical Materials. Methods for Determining the Moisture Resistance and Water Resistance. Russian State Standard 27473-87.

[16] Bessonov, M. I., Koton, M. M., Kudryavzev, V. V., and Layus, L. A. 1983. Polyimide-Klass Termostoykikh Polymerov. Leningrad: Nauka.

[17] Keshtov, M., Lopatin, A., and Marochkin, D. 2012.
"Conjugated Poly (Fluoroalkyl 3-Thienylacetate)s Synthesized in Supercritical Carbon Dioxide." Rus. J. Doklady Chemistry 443: 101-106.

[18] Rusanov, A. L., Komarova, L. G., and Prigozhina, M. P. 2006. "New Fluorinated Polyimides." Polymer Sci. Ser. B. 48 (7-8): 209-212.

[19] Korobova, N., Timoshenkov, S., Titov, A., Dolgovykh, Y., Tikhonov, K., and Naing, S. M. 2013. "Angular Rate Sensors with Conformal Flexible Multilayer Polymer Wiring Boards." Advanced Materials Research 630: 344-347.

[20] Gavrilova, N. D., Bradulina, L. G., Vigodskii, Y. S., and Matieva, A. M. 2001. "Dielectric Spectroscopy of Par-PMAA Films." Ferroelectrics 258: 123-128.

[21] Niklasson, G. A., Serbinov, I. A. 1988. "Dielectric Properties of Pyrolysed Polyimide Films." Mat. Sci. 23: 2601-2606.

[22] Fu, G. D., Wang, W. C., Li, S., Kang, E. T., Neoh, K. G., Tseng, W. T., et al. 2003. "Nanoporous Low- $\kappa$ Polyimide Films Prepared from Poly (Amic Acid)s with Grafted Poly (Methylmethacrylate)/Poly (Acrylamide) Side Chains." Mater. Chem. 13: 2150.

[23] Yu, H. C., Kumar, S. V., and Song, Y. K. 2011. "Nanoporous Thin Films of Fully Alicyclic Polyimides." Macromol. Research 19 (12): 1272-1277.

[24] Zhubanov, B. A., Kravtsova, V. D., Imanbekov, K. L., and Li, E. O. 2012. "Porous Film Materials Main Methods of Preparation and Application." Chem. J. of Kazakhstan 4: 20-38.

[25] Bekmagambetova, K. 2010. "Enhancement of Power Equipment and Power Lines Technical and Economic Index." Doctor thesis, Almaty University of Power Engineering and Telecommunication.

[26] Kochnev, A. M., Zaikin, A. E., Galibeev, S. S., and Arkhireev, V. P. 2003. Physical and Chemistry of Polymers. Kazan: Fen.

[27] DuPont ${ }^{\mathrm{TM}}$ Kapton. Polyimide Film Specifications. http://www.dupont.com/content/dam/assets/products-andservices/membranes-films/assets/DEC-Kapton-general-sp ecs.pdf (Accessed Feb. 17, 2015). 